\title{
Cost and benefit analysis of sugarcane production in Khyber Pakhtunkhwa Province of Pakistan
}

\author{
Bilal Ahmad ${ }^{1}$ \\ ${ }^{1}$ Affiliation not available
}

May 14, 2020

\begin{abstract}
The current study is based on the assessment of sugarcane farming in Khyber Pakhtunkhwa province. From the study, it is clear that the region has high potential of sugarcane production if the right inputs are provided since the demand for sugar in Khyber Pakhtunkhwa and other countries is high. The study is based on both primary and secondary information gathered from the region. Econometric methods of data analyses have been employed. In the study, the goals are to establish the cost and revenue gain in sugarcane cultivation, establish the resource use efficiency in sugarcane production and to examine the constraints faced by Farmers and the appropriate suggestion to overcome these constraints and improve their earnings. From the study, it is evident that efficient production of sugarcane is profitable as revenues exceed costs. Nevertheless resource use efficiency is low due to lack of modern production processes. Low rainfall, labor shortage and lack of access to inputs are the key constraints. To address these challenges irrigation should be enhanced and modern production processes adopted.
\end{abstract}

\section{Introduction}

Sugarcane is among leading cash crops of the world, and it grown in over 100 countries. Pakistan, India, Brazil, China and Thailand are major producers of sugar cane. In Khyber Pakhtunkhwa sugar cane plays an important role in uplifting the socioeconomic conditions of farmers. Rapid growth and expansion of the sugar industry has contributed significantly to the economic development of Khyber Pakhtunkhwa. Sugarcane is a big source of earning to the Khyber Pakhtunkhwa government since the crop brings billions of rupees to the country in terms of taxes and duties ${ }^{7}$. However, sugarcane farming requires huge resources in terms of extensive labor and capital. It is one of the leading constraints faced by many farmers, reducing their production and earnings 5 .

In Pakistan, sugarcane is grown on nearly 1.2 million hectares providing the raw material used by 90 sugar mills ${ }^{7}$. The sugarcane industry is the second biggest agriculture -based industry coming behind textiles industries ${ }^{6 .}$ Data from the Pakistan Sugar Mills Association (PSMA) and Ministry of National Food Security and Research (MNFSR) projects that in 2018/2019 financial year, sugarcane production will be 72 million tons, a decline of $12 \%$ from the previous year ${ }^{7}$. The main provinces of sugar production in Pakistan includes, Punjab accounting for $65 \%$, Sindh 25\%, and Khyber Pakhtunkhwa 10\%. It is worth noting that in spite of the decline in production, the demand for sugar is still high both locally and internationally.

Khyber Pakhtunkhwa province as stated is a key sugarcane growing region in Pakistan. Farmers decide for sugarcane farming in autumn or spring, though autumn planting offers better results owing to a longer growing season. Farmers in Khyber Pakhtunkhwa mainly plant their sugarcane during spring and harvest between eight and ten months later. Sugarcane yields per hectare in Khyber Pakhtunkhwa are relatively low ${ }^{7}$. This is caused by water shortage, irregular application fertilizer and pesticide and lack of high yielding sugarcane varieties7. Below is data showing sugarcane production on Khyber Pakhtunkhwa districts between in 2014/2015 and 2015/2016. 


\begin{tabular}{|l|c|c|c|c|c|c|}
\hline Districts & \multicolumn{3}{|c|}{$\mathbf{2 0 1 5 - 1 6}$} & \multicolumn{3}{c|}{ 2014-15 } \\
\hline & Area & Production & Yield & Area & Production & Yield \\
\hline Peshawar & 8134 & 422998 & 52 & 11376 & 568800 & 50 \\
\hline Charasadda & 31115 & 1442903 & 46.37 & 30012 & 1368221 & 45.58 \\
\hline Nowshera & 5263 & 270003 & 51.30 & 4260 & 219279 & 51.47 \\
\hline Mardan & 30915 & 1369273 & 44.29 & 30689 & 1381285 & 45 \\
\hline Swabi & 2253 & 86783 & 38.51 & 1651 & 64507 & 39.07 \\
\hline Kohat & 133 & 4631 & 34.81 & 117 & 4074 & 34.82 \\
\hline Hangu & 10 & 400 & 40 & 20 & 510 & 25.50 \\
\hline Mansehra & 8 & 194 & 24.25 & 7 & 165 & 23.57 \\
\hline Haripur & 102 & 3212 & 31.49 & 112 & 3527 & 31.49 \\
\hline
\end{tabular}

Table 1: Sugar production in various districts of Khyber Pakhtunkhwa province

Sugarcane commercial farmer of the region is mainly concerned about securing good margin between the cost of production and the earnings from his crop. Thus, to validate the continuance a farmer should earn net profits that are above the total cost of production. It is on this bases that the study is of critical importance for the farmers to know their production cost. However, it is important to note that the cost of production and earnings from sugarcane differ from one region to another and among different categories of farmers.

The current study was undertaken to achieve the underlined specific objectives:

1. To establish the cost and revenue gain in sugarcane cultivation.

2. To establish the resource use efficiency in sugarcane production.

3. To examine the constraints faced by Farmers and the appropriate suggestion to overcome, these constraints and improve their earnings.

\section{Material and Methods}

The study is carried out in form of exploratory research. It will be carried out on a sample of four districts from the many districts in Khyber Pakhtunkhwa. The study was carried out based on data that was collected using interviews on ten farmers in each district. Questionnaires were also issued to ten farmers in each district, aimed at identifying the costs and challenges they face in sugar cane production and the corresponding benefits.

\section{The study area}

The focus of the study will be on Khyber Pakhtunkhwa. The region is located in North West of western Khyber Pakhtunkhwa. It is bounded on the western side by Afghanistan. The province is 74,521 kilometer squares and has a population of 30.5 million people. The region has high level of variations in terms of elevation. The region experiences arid and semi-arid conditions often. As a result, many of the locations in this area are susceptible to drought. Most of Khyber Pakhtunkhwa falls in the arid and semi-arid region ${ }^{8}$. While annual rainfall is as low as $450 \mathrm{~mm}$ per year in some regions, other regions in Khyber receives up to $1500 \mathrm{~mm}$ per year. The rainfall recordings in various meteorological stations in Khyber Pakhtunkhwa are summarized below ${ }^{9}$

\begin{tabular}{llllll}
\hline Meteorological station & Minimum rainfall $\mathbf{( m m})$ & Maximum rainfall $\mathbf{( m m})$ & Mean & Standard deviation \\
\hline Balakot & 372.4 & 2488.3 & 1588.9 & 367.3 \\
Bannu & 151.3 & 621.6 & 361.9 & 140.2 \\
Cherat & 192.4 & 1285 & 625.1 & 201.9 \\
Chitral & 214.4 & 779 & 458.8 & 126.8 \\
D.I. Khan & 139.5 & 756.3 & 320.2 & 116.7 \\
Dir & 911.4 & 2149 & 1421.4 & 258.4 \\
Drosh & 349 & 8672 & 572 & 122.1 \\
Kakul & 940 & 1759.4 & 1352.5 & 193.5 \\
Kalam & 856.1 & 1356.5 & 1023.3 & 153.4 \\
\hline
\end{tabular}


Source: Rahnman, \& Rahman (2018).

While there are many other meteorological centers in the region, the focus of this study will be on the information gathered from the above stations.

\section{Data analyses}

Quantitative data was analyzed through econometrics using excel. Both descriptive and inferential statistics were generated. Measures of central tendency were analyzed. From the analyses, it was evident that unreliability of rainfall was a big challenge in the region. Based on the data provided on rainfall trends, it is evident that Khyber Pakhtunkhwa is characterized with low rainfall levels. This is one of the challenges that farmers in the country faces. It is worth noting that for sugarcane to grow, the need high water volume. The implication is that for farmers in the region to engage in sugarcane production successfully they would need to invest in irrigation ${ }^{4}$. As rainfall becomes erratic in Khyber Pakhtunkhwa, most of the residents are seeking irrigation as the main solution to the rainfall shortage. In 2017, the Asian Development Bank (ADB) approved $\$ 275$ million for irrigation promotion in Khyber Pakhtunkhwa. It was to be managed by Indus Rivera System Authority which is the agency tasked with promoting water distribution. Many farmers in the area indicate that the lack of adequate water in the region has made living there very difficult. Some of the residents are often pushed to sell their animals when dry season makes it difficult to access animal feed and water. Lack of the right technology is also a challenge in the production of food including sugarcanes. As a result, there is a move by the agency tasked with irrigation promotion to adopt modern farming technologies. These technologies will ease sugarcane farming in the region.

\section{Analyses tools}

The assessment of the impact that rain has on the production of sugarcane is assessed through the use of these equations.

Resource use efficiency

$\mathrm{MVPi}=\mathrm{B}{ }^{\mathrm{Y} / \mathrm{X}_{\mathrm{XP}}}{ }^{\mathrm{y}}$

In this case, $\mathrm{MVPi}=$ marginal value product of the $\mathrm{i}^{\text {th }}$ input.

$\mathrm{Y}$ is the geometric mean of the value of the outputs. In this case, the value is in rupees

$\mathrm{X}$ is the geometric mean of the $\mathrm{i}^{\text {th }}$ input which is also in rupees.

$\mathrm{Bi}$ is the estimated coefficient or the production elasticity in regards to the Xi input.

\section{Garret's ranking technique}

The questionnaires issued to the farmers provided significant information regarding sugarcane farming in Khyber Pakhtunkhwa. The opinions of such farmers were analyzed through the use of the Garret's ranking technique. The ranking approach was used in assigning the opinions of the farmers' statistical values. The percentage position as assessed through this formula is

$100 *\left(\mathrm{R}^{\mathrm{IJ}}-0.5\right) / \mathrm{N}$

$\mathrm{R}^{\mathrm{ij}}$ is the rank assigned to the $\mathrm{i}^{\text {th }}$ constraint by $\mathrm{j}^{\mathrm{th}}$ individual. On the other hand, $\mathrm{N}^{\mathrm{j}}$ is the number assigned to constraints identified by the $\mathrm{j}^{\text {th }}$ individual. The estimation of percentages then led to the conversion of such percentages to the numbers through the use of the Garret table. The constraint that had the highest mean was taken to be the one that had the greatest impact on the phenomena under study.

\section{Results and discussions}

Upon the assessment of the analyzed information, it is clear that farmer in the region spent $40 \%$ of their investment in farming in financing the operating costs. $10 \%$ was used in machineries and $20 \%$ were used on the development of irrigation systems. Thirty percent was used in the acquisition of planting materials and fertilizers among other inputs. The production function is thus summarized as below 
Cost $=0.4 \mathrm{X} 10+0.1 \mathrm{X} 2+0.2 \mathrm{X} 3+0.3 \mathrm{X} 4$. This indicates the total costs that were incurred by the farmers in the sugarcane production process. The $95 \%$ confidence value for the computation indicated that its findings were reliable. It is worth noting that all of the variables may be altered in one way or another to come up with the most objective cost equation. On the other hand, the total sales can also be expressed in the equation sales $=\mathrm{YP}$ where $\mathrm{y}$ refers to the total units of sugarcane produced ion kilograms and $\mathrm{p}$ is the price of one kilogram of the sugarcanes. The implication is that $0.4 \mathrm{X} 10+0.1 \mathrm{X} 2+0.2 \mathrm{X} 3+0.3 \mathrm{X} 4=\mathrm{YP}$ in order for the organization to break even. This implies that the entity ought to produce more than this if it is to generate profits. Sugarcane farming in Khyber Pakhtunkhwa is only justified if the farmers can get high level of returns in this activity as compared to other areas where they could have directed their efforts. The typical income statement provided by one of the respondents, which was highly similar in terms of patterns to that of the other respondents in the study is as presented below

\begin{tabular}{ll}
\hline Variable & Cost in Rupees \\
\hline Labor costs & 6000 \\
Cost of machine services & 12000 \\
Irrigation costs & 10000 \\
Tools, fertilizers and plants & 15000 \\
Total costs & 43000 \\
Total revenue & 63000 \\
Total revenue-Total cost & 20000 \\
\hline
\end{tabular}

As indicated above, it is clear that when done well, the earnings from sugarcane farming are found attractive by the farmers. Nevertheless, the above case is for a farmer who has access to irrigation facilities. The sugarcanes are left to grow for a period of nine months before they are harvested. In spite of this, there is significant change in the quantity of rainfall. The implication is that farmers who lack access to irrigation may end up having their production decline. Lack of water is the largest constraint that farmers in Khyber Pakhtunkhwa face, something that makes the sugarcane farming highly unprofitable. Equally, it is evident that the cost of farming sugarcane is high. As a result, the farmers will only engage in sugarcane production if they have access to funds to finance the farming. Nevertheless there is high level of profit margin of up to $30 \%$ that individuals who invest in sugarcane farming realize. This implies that when all the necessary inputs are available, sugar cane farming is a profitable business in Khyber Pakhtunkhwa. The cost of farming sugar canes is lower than the earnings based on the assumption that such sugarcanes are not adversely affected by drought. In the analyses, various elements that influences sugarcane farming are ranked below by the Garret ranking scale

\begin{tabular}{lll}
\hline & Mean scores & Garret ranking \\
\hline Access to family labor & $60 \%$ & VIII \\
Access to external sources of labor & $80 \%$ & III \\
Access to the right farming technology & $65 \%$ & VII \\
Good price for the products & $79 \%$ & IV \\
Access to inputs such as the right tubers and fertilizers & $82 \%$ & II \\
Unavailability of adequate funding & $68 \%$ & VI \\
Attack by pests and disease. & $70 \%$ & V \\
Access to rain water/water for irrigation ${ }^{10}$ & $85 \%$ & I \\
\hline
\end{tabular}

As indicated in the above rankings, it is evident that access to water is a critical element that influences production of sugarcane in Khyber Pakhtunkhwa. In particular, it is evident that many of the areas in Khyber Pakhtunkhwa are arid or semi-arid ${ }^{7}$. This implies that farmers within the country who intends to engage in sugarcane farming must seek ways of accessing water for irrigation which is not always easy. 
Equally it is evident that even access to inputs and labor is a challenge in sugarcane production within the region. Farmers would like to put the bigger part of their farms in the production. Moreover, even with enhanced production capabilities, it is clear that farming of sugarcanes will not be sustainable if the prices are too low. In order for individuals to engage in successful sugar cane farming, it there is a need for attractive profit margins. It is worth noting that during the peak periods, labor shortage was a big problem. Farmers rely on casual laborers to assist in the harvesting process. They thus need to have adequate cash to ensure that they can harvest the products on time and deliver top the market.

In sugarcane production, it is evident that the use of the right production process will dictate the success of sugar production within Khyber Pakhtunkhwa. For instance, a study was carried out on the intercropping of sugarcane with other products such as Canola in Khyber Pakhtunkhwa ${ }^{3}$. Intercropping of sugarcane with other products should be done in the right way if the productivity of firms is to be sustained. Different forms of canes were assessed on basis of their length and diameter when intercropped with Canola. Cane length is a key determinant of success in the production process. It was evident that sugar cane length was enhanced when sugarcanes were grown without intercropping. When sugarcane is intercropped with too many other plants, their length and quality gets affected. This has the potential of cutting the overall level of returns that farmers realize through sugarcane farming. It is thus recommended that farmers in Khyber Pakhtunkhwa should set aside separate rows where sugarcanes are grown on their own as opposed to intercropping. More over availability of water and fertilizers equally positively enhances the girth and length of sugarcanes ${ }^{8}$.

Price of sugar and availability of the market for sugar will be a key determinant of success in sugarcane farming within Khyber Pakhtunkhwa. Despite increasing export subsidies for sugar that are aimed at boosting sugar cane and sugar production in Khyber Pakhtunkhwa, it is clear that there is still low level of sugar that is currently being exported. It is one million metric tons of sugar that are currently exported from Khyber Pakhtunkhwa to other countries. In 2018/2019 year, the stock of sugar for export in Khyber Pakhtunkhwa was projected to be 4.7 million metric tons. The implication is that there is still high demand for sugar in the market yet farmers have not been in a position to meet these demands due to the existence of multiple constrains in the production process. It is worth noting that challenges are not just in the production process. There have been significant delays in the payment of sugar farmers. Such farmers rely on such payments in preparation for the incoming season. When the payment is delayed, the farmers are thus not able to prepare their farms on time something that hinders the attainment of a smooth production cycle.

\section{Summary of findings}

Based on the analysis of the information gathered in this study, it is evident that enhanced funding of the farmers and the government move to invest in irrigation will significantly boost the profitable and sustainable exploitation of profitable opportunities in the organization. Precision farming and drip irrigation will play an important role in enhancing productivity in the highly arid areas of Khyber Pakhtunkhwa. Currently, Khyber Pakhtunkhwa is faced with water crisis. It is likely to wreak havoc in the country unless urgent measures are undertaken. Indus River System Authority (IRSA) has pointed at the grave water shortage facing the country. This is highly pronounced even in areas where there has been significant access to water such as in the Indus Basin Irrigation System. The basin has in the past been used for summer time irrigation. Currently, signs of water shortage in the country are ubiquitous. Resource depletion and contamination has significantly contributed to this challenge in the past decade. These problems has deteriorated as the leadership focus on seizing of power as opposed to coming up with a reliable solution. Construction of new infrastructure for water storage is thus currently an urgent need. At the same time, human labor may not be sufficient in large plantations. As a result, there will be need use of machinery in sugarcane farming activities in the region in order to ease the labor challenges ${ }^{1 \cdot}$ Modern machines will facilitate the cultivation of large tracks of land within a short time. It will also make harvesting of the sugarcanes easier ensuring that they are delivered to the market on time before they deteriorate in quality. Modern farming methods and technology will be a key ingredient to successful farming of sugarcanes within Khyber Pakhtunkhwa. 
Government policy will be a key determinant of successful farming of sugarcane within Khyber Pakhtunkhwa. It is worth noting the efforts that various stakeholders in the sector are making to boost sugarcane farming in the country. Through development of effective policies, the government will be able to develop farming environment that promotes irrigation based farming using modern farming methods ${ }^{2}$. This will ensure that farmers' efficiency in resource use is enhanced and the level of profitability from their operations is high. High returns will motivate many farmers to invest in sugarcane farming in the country.

\section{Conclusion}

Based on the above study, it is evident that the objectives of the study have been met. The cost and revenue gain involved in sugarcane farming in Khyber Pakhtunkhwa has been identified. It is clear that the sales revenue in sugar cane farming exceeds the costs assuming that all of the necessary inputs of production are available. Nevertheless, in many cases, such inputs such as rain water are not available prompting a need for the use of irrigation in the production process. Equally, resource use efficiency in production has been assessed. It is clear that proper utilization of resources will enable farmers in the sugarcane farming sector to successfully exploit resources amidst the shortage of resources in the sector. The lack of modern technology hinders the realization of efficiency in the production of sugar cane. Finally, the objective of assessing constraints that face farmers in the sugarcane growing areas has been attained. Such farmers are faced with challenges such as low funding, low access to labor, insufficient rainfall, and lack of access to adequate inputs that include tubers and fertilizers and delay in sugarcane payments after delivery. Addressing of these challenges will enhance the success of sugarcane farming in Khyber Pakhtunkhwa.

\section{Data Accessibility Statement}

Cost and Benefit analysis data: Figshare DOI: 10.6084/m9.figshare.12292802

Data of Variables: Figshare: https://figshare.com/s/c47762acb2bb44d0e114

References

1. Heinz, D. J. (2015). Sugarcane improvement through breeding. Amsterdam: Elsevier Science

2. Humbert, R. P. (2014). The Growing of Sugar Cane . Amsterdam: Elsevier Science.

3. Khan, A., Khan, M., \& Khan, Q. (2012). Economic analyses of sugarcane intercropping with canola. Pak. J. Agri. Sci., 49(4), 589-592

4. Laycock, A. C. U. (2011). Irrigation s - design, planning and construction . London: Cabi

Publishing

5. Nazir, A., Jariko, G. A., \& Junejo, M. A. (2013). Factors affecting sugarcane production in

Khyber Pakhtunkhwa. MPRA Paper No. 50359

6. Peng, S. (2014). The Biology And Control of Weeds in Sugarcane. Saint Louis: Elsevier

Science.

7. Rehman, M S (2018) Khyber Pakhtunkhwa: Sugar Annual report 2018. Retrieved from

https://gain.fas.usda.gov/Recent\%20GAIN\%20Publications/Sugar\%20Annual_Islamabad_Khyber Pakhtunkhwa_4-19-2018.pdf

8. Rahnman, G., \& Rahman, A. (2018). Spatial and temporal variation of rainfall and drought in Khyber Pakhtunkwa. Arabian Journal of Geosciences, 11(3), 1

9. Singh, S., Singh, H., Kumari, Meera and Kumar, Balwat (2018). Economic analyses of 
production, resource use efficiency and constraints analyses of sugarcane cultivation in east cmparana district of Bihar.Int.J.Curr.Microbiol.App.Sci (2018) 7(10), 512-519

10. Unesco. (2018). Nature-based solutions for water. Paris: Paris United Nations Educational, Scientific and Cultural Organization 